\title{
Impact of a Community Pharmacist-Delivered Information Program on the Follow-up of Type-2 Diabetic Patients: A Cluster Randomized Controlled Study
}

\author{
Yves Michiels - Olivier Bugnon - Annie Chicoye - Sylvie Dejager · \\ Christine Moisan · François-André Allaert • Catherine Hunault • \\ Laura Romengas $\cdot$ Hubert Méchin · Bruno Vergès (1)
}

Received: March 13, 2019 / Published online: May 2, 2019

(c) The Author(s) 2019

\begin{abstract}
Introduction: Low-quality communication between patients and care providers and limited patient knowledge of the disease and the therapy are important factors associated with poor glycemic control in patients with type 2 diabetes. We conducted a multicenter study to determine whether structured and tailored information delivered by pharmacists to type 2 diabetic patients could improve patient
\end{abstract}

Enhanced Digital Features To view enhanced digital features for this article go to https://doi.org/10.6084/ m9.figshare.7964879.

Electronic Supplementary Material The online version of this article (https://doi.org/10.1007/s12325$019-00957-y)$ contains supplementary material, which is available to authorized users.

Y. Michiels · O. Bugnon

Community Pharmacy, School of Pharmaceutical

Sciences, University of Geneva, University of

Lausanne, Lausanne, Switzerland

A. Chicoye

Institut d'Études Politiques de Paris, Paris, France

S. Dejager · C. Hunault

MSD France, Courbevoie, France

F.-A. Allaert

Evaluation Chair BSB-Cenbiotech, Dijon, France

L. Romengas · H. Méchin

Observia Group, Paris, France treatment adherence, hemoglobin A1c (HbA1c) levels and knowledge about diabetes.

Methods: One hundred seventy-four pharmacies were randomized to deliver an educational program on diet, drug treatment, disease and complications during three 30-min interviews over a 6-month period, or to provide no intervention, to type 2 diabetic patients treated with oral antidiabetic agents. Medication adherence was assessed by measuring the medication possession ratio and diabetes control by collecting HbA1c values. Levels of patient treatment selfmanagement and disease knowledge were assessed using self-questionnaires.

Results: Three hundred seventy-seven patients were analyzed. The medication possession ratio, already very high at baseline in the intervention $(94.8 \%)$ and control (92.3\%) groups, did not vary significantly after 6 months with no

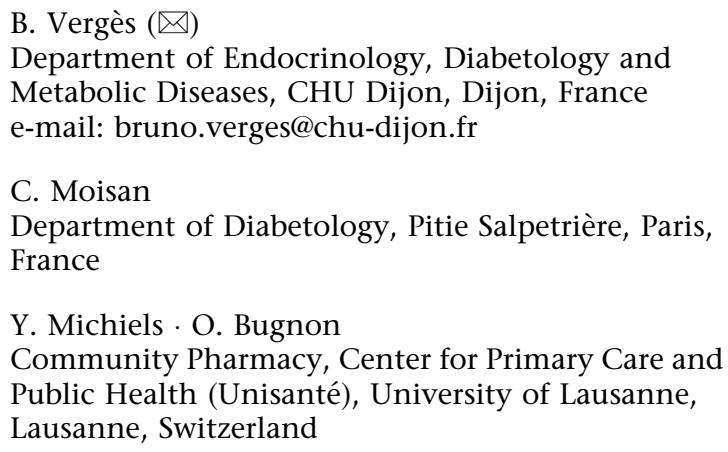


difference between the two groups. Significant decreases in HbA1c were observed in both groups at 6 months $(p<0.001)$ and 12 months $(p<0.01)$, with significantly greater changes from baseline in the intervention group than in the control group at 6 months $(-0.5 \%$ vs. $-0.2 \%, p=0.0047)$ and 12 months $(-0.6 \%$ vs. $-0.2 \%, p=0.0057)$. Patients in the intervention group showed greater improvement in their ability to self-manage treatment $(+4.86$ vs. $+1.58, p=0.0014)$ and in the extent of their knowledge about diabetes ( +0.6 vs. +0.2 , $p<0.01$ ) at 6 months versus baseline compared with the control group.

Conclusion: Tailored information provided by the pharmacist to patients with type 2 diabetes did not significantly improve the already high adherence rates, but was associated with a significant decrease in HbA1c and an improvement of patient knowledge about diabetes.

Trial Registration: ISRCTN33776525.

Funding: MSD France.

Keywords: Disease knowledge; Glucose control; Patient information; Pharmacist; Type 2 diabetes

\section{INTRODUCTION}

Diabetes is a progressive and chronic disease accounting for almost $15-25 \%$ of healthcare spending depending on the country $[1,2]$. The prevalence of diabetes is increasing, and the many complications that occur when the disease is insufficiently controlled contribute substantially to these healthcare costs. Despite significant improvements in the follow-up of type 2 diabetes (T2D) patients, results from the ENTRED 2007 French national survey of people treated for diabetes, those from the PANORAMA European study and even those from the American National Health and Nutrition Examination Survey all indicate that levels of glycemic control remain insufficient, with too many patients $(41 \%, 42.3 \%$ and $50 \%$, respectively) having hemoglobin A1c (HbA1c) values above the recommended target of 7\% [3-6]. Inadequate dietary and physical activity practices, due to a low level of knowledge about the disease and its treatment as well as poor medication adherence, may contribute to these
HbA1c values [6]. In particular, a close correlation has been identified between Morisky adherence questionnaire scores and HbA1c levels [7]. A 25\% improvement in adherence has been reported to translate into a $0.34 \%$ reduction in HbA1c levels [8]. Poor adherence has also been shown to increase the risk of long-term complications, acute complications, hospitalizations and mortality and to be associated with higher healthcare costs [7-12]. Moreover, nonadherence has been identified as a predictive factor for intensification of treatment among diabetic patients [11, 13]. Adherence, therefore, seems to be one of the key components of successful treatment of a chronic disease such as T2D [6, 14-16]. Unsatisfactory patient-healthcare provider relationships and poor patient knowledge about their treatment have been correlated with nonadherence to treatment and failure to meet patient needs [17]. These factors have been highlighted in many T2D studies as contributory factors to unsatisfactory drug effectiveness [15]. Any action taken by a health professional involved in the care of patients with T2D should therefore be designed to maintain or improve patient education and patient-healthcare provider relationships $[17,18]$. Pharmacists may make an important contribution to the successful management of patients with T2D. However, only a few studies involving limited numbers of patients have analyzed the impact of pharmacist interventions on the management of T2D and its treatment during semistructured interviews using the InformationMotivation-Behavioral (IMB) model [19-24]. Thus, we conducted a large multicenter study, IPHODIA (French acronym for Information des Pharmaciens d'Officines sur le Diabète), to assess the impact of an information program delivered by the pharmacist on patients' medication adherence and ability to self-manage their treatment as well as its impact on diabetes control and the level of disease knowledge among patients with T2D.

\section{METHODS}

\section{Study Design and Setting}

This prospective, multicenter, randomized controlled trial (RCT) was conducted in France 
from February 2014 to June 2016 in pharmacies recruited from a sample of 1500 pharmacies representative-in terms of region (urban versus rural areas) and annual revenue-of the 22,500 pharmacies located in France. These pharmacies were contacted by email or phone to participate in the study and selected based on the following criteria: motivation, interest in delivering structured and tailored information to patients, willingness to participate and representativeness criteria. The study protocol was submitted to the Committee for the protection of persons (CPP Centre Est 1-Dijon), which considered that no informed consent was required according to French law. As per law, approval for processing of personal health data was obtained from the French Data Protection Agency [Commission Nationale de l'Informatique et des Libertés (CNIL)] following prior consultation of the Advisory Committee on Data Processing in Health Research [Comité Consultatif sur le Traitement de l'Information en matière de Recherche dans le domaine de la Santé (CCTIRS)], which gave a favorable opinion.

\section{Participant Recruitment and Randomization}

The selected pharmacies were randomly allocated in two groups: when dispensing the usual prescribed treatment, one group proceeded according to the usual/standard practice (control group), whereas the other group provided structured and tailored information related to diabetes care to the patient (intervention group). Each participating pharmacy was requested to consecutively enroll at least 6 patients with a maximum of 12 .

Included patients were adults with T2D and an HbA1c level $>7 \%$ at baseline, being treated with no more than three different oral antidiabetic drugs. To limit the drop-out rate, only regular customers ( $>6$ months) were to be recruited into the study. Patients with malignant tumors or severe psychiatric disorders, patients treated by insulin or injectable antidiabetic drugs, or any patients participating or having already participated in a therapeutic education program were excluded from the study.

\section{Intervention}

Prior to the inclusion of patients, pharmacists participating in the intervention program received information on the study by phone and were trained face to face. They were provided with a guide explaining how to perform the interviews. The pharmacists then delivered structured and tailored information on three different topics (diabetes diet, medication management and diabetes complications) during three pharmaceutical interviews. These interviews lasted $30 \mathrm{~min}$ and were divided into two parts: (1) first, the pharmacist performed a global assessment of the disease status of the patient; (2) he/she then gave the patient an information brochure dealing with the topic of interest and started an open discussion with the patient on this topic.

\section{Study Plan}

The study took place over 1 year and included nine visits, one inclusion visit (V0), seven dispensation visits (V1-V7) at a rate of one per month for the 6-month intervention period and one follow-up visit at the end of the 6-month follow-up period (V8). Patient data (demographics, treatment, etc.) were collected at V1 for all patients. At each visit, the pharmacist dispensed the medication boxes prescribed for a 1-month period, asked the patient to bring back the boxes at the next visit and counted the number of pills remaining in the returned boxes. Pharmaceutical interviews were performed at V1, V3 and V5 in the intervention group only. No other information was delivered to patients in the intervention group during the follow-up period.

\section{Evaluation Criteria of Intervention Efficacy}

\section{Main Evaluation Criterion: Adherence to Medication}

Medication adherence was assessed by measuring the medication possession ratio (MPR) at each visit between V2 and V7. The MPR was calculated as the ratio of the number of pills 
taken by the patient to the number of pills that should have been theoretically taken within a time interval. Adherence was considered as very good when the MPR was $>80 \%$.

\section{Secondary Evaluation Criteria}

Diabetes Control The pharmacist collected data on HbA1c and LDL-c levels from biologic analysis results provided by the patients and asked the patients for their systolic (SBP) and diastolic blood pressure (DBP) values at V1 and at the end of the intervention (V7) and followup (V8) periods.

\section{Ability of the Patients to Self-Manage Their} Treatment The ability of patients to selfmanage their treatment, and therefore their potential to be adherent to their treatment "a priori," was assessed by asking the patients to complete the "TOP" questionnaire (TOP: Test d'Observance Pharmaceutique) themselves at the beginning (V1) and end of the intervention period (V7). This questionnaire was centered around the relationship between diabetic patients and their pharmacists, their ability to self-manage their treatment and the knowledge acquired during the dispensation of the drugs (Table S1). It comprised 20 items classified into two parts: the first one evaluated the level of communication between the patient and healthcare professionals (pharmacist and physician) regarding management of his/her treatment, and the second part evaluated the general knowledge of the patient about the disease and its treatment. Each answer was scored using a four-point scale: never $=1$; rarely $=2$; often $=4$; always $=5$, and a global score was calculated as the sum of all answers, with a maximum of 100 points. The ability of patients to self-manage their T2D medication was categorized depending on the score obtained, as follows: below 40, low ability to self-manage treatment; from 40 to 59 , moderate ability to self-manage treatment; from 60 to 79 , good ability to self-manage treatment; from 80 to 100 , very good ability to self-manage treatment.

Level of Patient Knowledge of Diabetes The patients assessed their level of knowledge about their disease and its management by completing a self-administered questionnaire at V1 and at the end of the intervention (V7) and followup periods (V8). This knowledge acquisition questionnaire on diabetes, which contains ten statements related to diabetes care/management, was developed internally based on the structured and tailored information delivered during the pharmaceutical interviews (Table S2). The patient had to fill in the questionnaire by answering true or false. The mean number of correct answers was reported.

Change in Diabetes Treatment As a change in diabetes treatment may have an impact on the MPR and biologic analysis results, any change in diabetes medication at any point during the study period (V1-V8) was reported and quantified. The following situations were considered as a change in diabetes treatment: change in the posology of the usual antidiabetic medication; substitution of the usual antidiabetic medication by another molecule from the same therapeutic class or from a different one; addition of a new antidiabetic medication.

\section{Sample Size Analysis}

To show a mean difference in the impact of the pharmacist's information on the MPR between groups of $10 \%$, with a mutual standard deviation of $25 \%$, a power of $90 \%$, a significance level of 0.05 and an inflation coefficient of $20 \%$ to take into account drop-out patients, it was calculated that at least 167 patients were needed in each group.

\section{Statistical Analyses}

Quantitative variables were described using averages, standard deviations, medians and quartiles and qualitative variables using the numbers and percentages of patients. Comparisons of means between groups were carried out by analyses of variance (ANOVA) using the Fisher-Snedecor test. Comparisons within groups were performed using the Student paired $t$-test. Percentages were compared using the chi-squared test or Fisher's test if the validity conditions of the test were not 
met. All statistical analyses were performed using SAS software, version 9.3. The level of significance was $5 \%$.

\section{RESULTS}

\section{Study Participants}

Based on a panel of 1500 pharmacies representative of the 22,500 pharmacies located in French territory, 1083 pharmacies were invited to participate in the study, and 273 pharmacies agreed to receive the study training. Of these, 99 dropped out because of a lack of time to manage both the study and their standard activities. Thus, 174 pharmacies (87 in each group) finally participated in the study and enrolled patients (Fig. 1). A total of 1021 patients were eligible and 528 were included in the study. Of these, 151 were excluded from the analysis, and 377 patients formed the full analysis set: 189 in the intervention group and 188 in the control group (Fig. 1).

\section{Demographic and Clinical Characteristics of Patients at Baseline}

Patients in the intervention and control groups were most often male $(54 \%$ and $61 \%$, respectively), about 65-66 years old, diabetic for $>10$ years with an HbA1c level of about 7.8\% and overweight [approximately $40.8 \%$ had a body mass index (BMI) $25-30 \mathrm{~kg} / \mathrm{m}^{2}$ ] or obese $\left(45.6 \%\right.$ had a BMI $\left.>30 \mathrm{~kg} / \mathrm{m}^{2}\right)$. One, two or three forms of oral antidiabetic medication (OAD) were each being taken by approximately a third of the patients. Biguanides were the main class of antidiabetic agents used by patients (93-96\%) (see Table 1 for more details). Patients' demographic and clinical characteristics at baseline did not differ significantly between the two groups.

\section{Adherence to Medication}

The MPR was $>80 \%$ in the intervention group and in the control group, both at baseline $(94.8 \pm 11$ and $92.3 \pm 15$, respectively, $p=0.0718)$ and at 6 months $(93.4 \pm 12.1$ and $91.9 \pm 13.2$, respectively, $p=0.25)$, which shows a high level of medication adherence. There was no statistical difference within groups between the MPR at baseline and 6 months ( $p=0.5296$ ). At 6 months, $87.3 \%$ and $87.2 \%$ of patients in the intervention and control groups, respectively, had an MPR $>80 \%$, with no difference between groups $(p=0.9843)$.

\section{Diabetes Control}

As shown in Table 2, the mean percentage $( \pm \mathrm{SD})$ of HbA1c at 6 months significantly decreased compared with baseline in both the intervention group $(p<0.0001)$ and control group $(p<0.001)$. The change from baseline was significantly greater in the intervention group than in the control group $(-0.5 \%$ vs. $-0.2 \%, p=0.0047)$. This encouraging result was confirmed at 12 months, with a $-0.6 \%$ decrease from baseline $(p<0.0001)$ in the intervention group compared with - $0.2 \%$ $(p<0.01)$ in the control group (difference between groups: $-0.4 \%, p=0.0057$ ) at the end of the 6-month "wash-out" phase during which patients did not receive any specific information.

The number of patients achieving HbA1c $<7 \%(<53 \mathrm{mmol} / \mathrm{mol})$ at 6 months was also higher in the intervention group than in the control group $(35.6 \%$ vs. $19.6 \% ; p=0.0013)$.

Regarding LDL-c and blood pressure values, there were no significant differences in the changes from baseline between groups at 6 months (LDL-c mg/dl: $10 \pm 30$ vs. $0 \pm 30$, $p=0.70$; DBP: $0.1 \pm 8.3$ vs. $1.2 \pm 9.4, p=0.37$; SBP mmHg: $-0.8 \pm 10.4$ vs. $-0.2 \pm 10.6$, $p=0.69$ ) or 12 months (LDL-c mg/dl: $0 \pm 40$ vs. $0 \pm 30, p=0.66$; DBP: $1.9 \pm 8.3$ vs. $-0.2 \pm 9$, $p=0.09 ; \quad$ SBP $\quad$ mmHg: $\quad 0.5 \pm 10.5 \quad$ vs. $-0.3 \pm 11.2, p=0.59$ ).

\section{Ability of the Patients to Self-Manage Their Treatment}

Changes in TOP scores during the course of the study are shown in Fig. 2. TOP global scores were high at baseline in both groups. They 


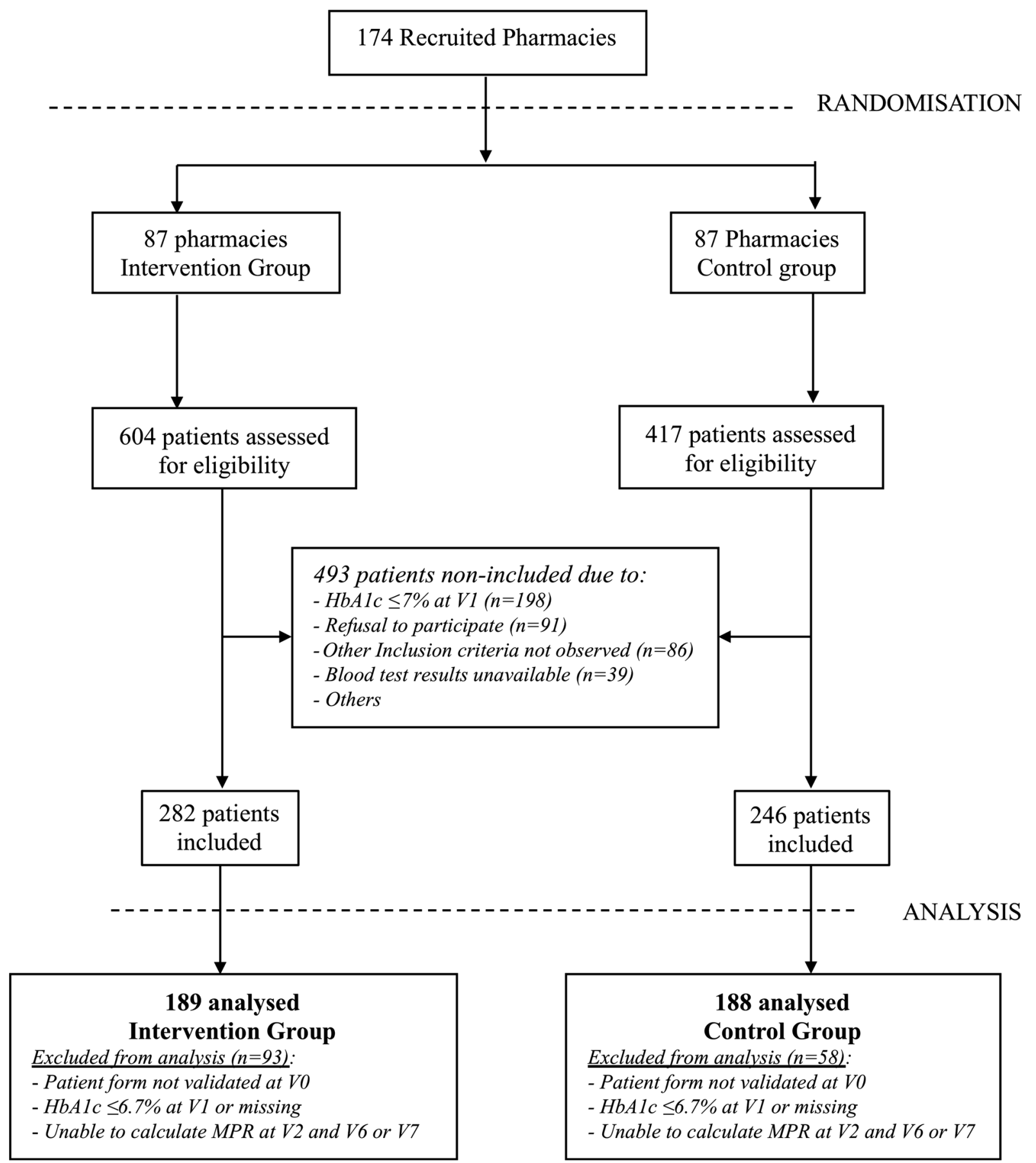

Fig. 1 Flow diagram of study participants: pharmacies and patients

increased significantly after 6 months compared with baseline in both the intervention group $(p<0.0001)$ and the control group $(p=0.017)$, with mean scores at 6 months significantly higher in the intervention group than in the control group $(80.1 \pm 9.2$ vs. $75.9 \pm 9.5$, $p=0.0004)$. The changes from baseline were significantly different between groups after adjustment for the score at baseline [4.86 (3.41-6.31) vs. $1.58(0.22-2.95), p=0.0014]$. 
Table 1 Demographic and clinical characteristics of patients at baseline

\begin{tabular}{|c|c|c|}
\hline $\begin{array}{l}\text { Demographic and } \\
\text { clinical characteristics }\end{array}$ & $\begin{array}{l}\text { Intervention } \\
\text { group, } \\
N=189\end{array}$ & $\begin{array}{l}\begin{array}{l}\text { Control } \\
\text { group, }\end{array} \\
N=188\end{array}$ \\
\hline Age $($ mean $\pm S D)$ & $65.1 \pm 11.4$ & $66.3 \pm 10.9$ \\
\hline Female, $n(\%)$ & $87(46)$ & $73(39)$ \\
\hline Male, $n(\%)$ & $102(54)$ & $115(61)$ \\
\hline $\begin{array}{l}\text { Body mass index (BMI) } \\
\quad(\text { mean } \pm S D)\end{array}$ & $30.1 \pm 5$ & $30.2 \pm 5.2$ \\
\hline \multicolumn{3}{|l|}{ BMI category, $n(\%)$} \\
\hline $18.5-25 \mathrm{~kg} / \mathrm{m}^{2}$ & $24(12.7)$ & $27(14.4)$ \\
\hline $25-30 \mathrm{~kg} / \mathrm{m}^{2}$ & $78(41.3)$ & $76(40.4)$ \\
\hline$>30 \mathrm{~kg} / \mathrm{m}^{2}$ & $87(46)$ & $85(45.2)$ \\
\hline $\begin{array}{c}\text { Diabetes anteriority (in } \\
\text { years) }(\text { mean } \pm S D)\end{array}$ & $10.7 \pm 8.2$ & $10.2 \pm 7.9$ \\
\hline Smoking, $n / N(\%)$ & $23 / 186(12.4)$ & $24 / 186(12.9$ \\
\hline $\begin{array}{l}\text { Alcohol consumption, } \\
n / N(\%)\end{array}$ & $30 / 187(16)$ & $49 / 185(25.9$ \\
\hline $\begin{array}{l}\text { Pill organizer usage, } n / N \\
\text { (\%) }\end{array}$ & $58 / 188(30.9)$ & $62 / 185(33.5$ \\
\hline $\begin{array}{l}\text { Oral antidiabetic } \\
\text { treatment, } n(\%)\end{array}$ & $N=188$ & $N=186$ \\
\hline Monotherapy & $57(30.3)$ & $64(34.4)$ \\
\hline Bitherapy & $74(39.4)$ & $79(42.5)$ \\
\hline Tritherapy & $57(30.3)$ & $43(23.1)$ \\
\hline
\end{tabular}

Type of antidiabetic treatment alone or in combination, $n(\%)$

\begin{tabular}{lll} 
Biguanides & $181(95.8)$ & $175(93.1)$ \\
Sulfonylurea & $92(48.7)$ & $88(46.8)$ \\
DPP-4 inhibitors & $95(50.2)$ & $86(45.7)$ \\
Glinides & $24(12.7)$ & $22(11.7)$ \\
$\begin{array}{l}\text { Alpha-glucosidase } \\
\text { inhibitors }\end{array}$ & $6(3.2)$ & $4(2.1)$ \\
$\begin{array}{l}\text { Antihypertension } \\
\text { treatment, } n / N(\%)\end{array}$ & $124 / 157(79.0)$ & $126 / 158$ \\
& & $(79.7)$ \\
\hline
\end{tabular}

Table 1 continued

\begin{tabular}{lll}
\hline $\begin{array}{l}\text { Demographic and } \\
\text { clinical characteristics }\end{array}$ & $\begin{array}{l}\text { Intervention } \\
\text { group, } \\
\boldsymbol{N}=\mathbf{1 8 9}\end{array}$ & $\begin{array}{l}\text { Control } \\
\text { group, } \\
\boldsymbol{N}=\mathbf{1 8 8}\end{array}$ \\
\hline $\begin{array}{l}\text { Hypolipidemic } \\
\text { treatment, } n / N(\%)\end{array}$ & $116 / 157(73.9)$ & $\begin{array}{c}121 / 158 \\
(76.6)\end{array}$ \\
$\begin{array}{l}\text { Biologic values (mean } \pm \mathrm{SD}) \\
\text { HbA1c \% }\end{array}$ & $7.9 \pm 1.0$ & $7.7 \pm 0.8$ \\
$\begin{array}{l}\text { Fasting plasma glucose } \\
\text { (g/l) }\end{array}$ & $1.6 \pm 0.4$ & $1.6 \pm 0.5$ \\
$\begin{array}{l}\text { Total cholesterol } \\
\text { (mg/dl) }\end{array}$ & $1.9 \pm 0.4$ & $2.0 \pm 0.7$ \\
$\begin{array}{l}\text { LDL-c (mg/dl) } \\
\text { Blood pressure (mean } \pm \text { SD) }\end{array}$ & $110 \pm 40$ & $110 \pm 50$ \\
$\begin{array}{l}\text { Systolic blood pressure } \\
\text { (mmHg) }\end{array}$ & $134.8 \pm 11.6$ & $136.1 \pm 11.3$ \\
$\begin{array}{l}\text { Diastolic blood } \\
\text { pressure (mmHg) }\end{array}$ & $78.1 \pm 9.3$ & $79.1 \pm 9.2$ \\
\hline
\end{tabular}

No significant differences in demographic or clinical characteristics were observed between the two groups at baseline

When specified, $N=$ number of patients for which data were available. Missing data were excluded from the analysis

When not specified, $N=$ total number of patients included in each group

Therefore, the intervention group switched from "good ability to self-manage treatment" to "very good ability to self-manage treatment."

\section{Knowledge Acquisition Results}

Levels of patient knowledge about their disease after 6 months of intervention increased significantly more in the intervention group than in the control group, with a change from baseline (adjusted for the number of correct responses at baseline) of +0.81 versus +0.18 $(p=0.0009)$, showing a greater improvement in levels of disease knowledge in patients who had received the structured and tailored information (Table 3). The mean number of correct answers was also significantly higher at 
Table 2 Parameters of diabetes control

\begin{tabular}{llll}
\hline & Intervention group & Control group & $p$ value \\
\hline HbAlc \% (mean \pm SD) & $n=160$ & $n=162$ & \\
Baseline & $7.9 \pm 1.1$ & $7.7 \pm 0.8$ & $0.11^{\mathrm{c}}$ \\
6 months & $7.4 \pm 1.0^{* * * *}$ & $7.5 \pm 0.8^{* * *}$ & $0.212^{\mathrm{c}}$ \\
12 months & $7.3 \pm 0.9^{* * * *}$ & $7.6 \pm 1.0^{* *}$ & $0.067^{\mathrm{c}}$ \\
Patients with HbAlc $<7 \%, n(\%)$ & & & \\
Baseline & $4 / 188(2.1)$ & $0 / 189(0)$ & $0.1230^{\mathrm{a}}$ \\
6 months & $57 / 160(35.6)$ & $32 / 163(19.6)$ & $0.0013^{\mathrm{b}}$ \\
LDL-c mg/dl (mean \pm SD) & $n=78$ & $n=74$ & \\
Baseline & $110 \pm 40$ & $120 \pm 60$ & $0.0840^{\mathrm{c}}$ \\
6 months & $100 \pm 30$ & $120 \pm 50$ & $0.0306^{\mathrm{c}}$ \\
12 months & $110 \pm 40$ & $110 \pm 50$ & $0.3665^{\mathrm{c}}$ \\
Systolic blood pressure, mmHg (mean \pm SD) & $n=119$ & $n=115$ & \\
Baseline & $134.4 \pm 11.6$ & $137.0 \pm 11.6$ & $0.0884^{\mathrm{c}}$ \\
6 months & $133.7 \pm 10.1$ & $136.8 \pm 9.6$ & $0.0160^{\mathrm{c}}$ \\
12 months & $134.9 \pm 10$ & $136.9 \pm 9.8$ & $0.1378^{\mathrm{c}}$ \\
Diastolic blood pressure, mmHg (mean \pm SD) & $n=118$ & $n=113$ & $79.9 \pm 8.2$ \\
Baseline & $78.5 \pm 8.7$ & $81.1 \pm 9.5$ & $0.2124^{\mathrm{c}}$ \\
6 months & $78.7 \pm 8.4$ & $79.9 \pm 7.8$ & $0.0405^{\mathrm{c}}$ \\
12 months & $79.8 \pm 8.3$ & $0.9315^{\mathrm{c}}$ \\
\hline
\end{tabular}

Within-group comparisons versus baseline performed using the Student's paired test: ${ }^{* *} p<0.01,{ }^{* * *} p<0.001$, ${ }^{* * * *} p<0.0001$

$n$ number of patients for which data were available. Missing data were excluded from the analysis

a Between-group comparisons of percentages performed using Fisher's test

b Between-group comparisons of percentages performed using the chi-squared test

c Between-group comparisons of means: analysis of variance (ANOVA Fisher-Snedecor)

12 months in the intervention group than in the control group $(8.8 \pm 1.2$ vs. $8.0 \pm 1.3$, $p=0.0003)$.

\section{Change in Diabetes Treatment}

No statistical difference in the number of patients having had their diabetes treatment changed over the whole study duration (from inclusion to 12 months) was noted between the two groups: $22.2 \%(42 / 189)$ of patients in the intervention group versus $17.6 \%(33 / 188)$ in the control group $(p=0.2562)$.

\section{DISCUSSION}

To the best of our knowledge, IPhODia is the first RCT performed in France to evaluate the effect of a pharmacist-delivered information program using an IMB model on patient adherence to treatment and disease knowledge. Adherence to medication and the ability of patients to self-manage their medication were 


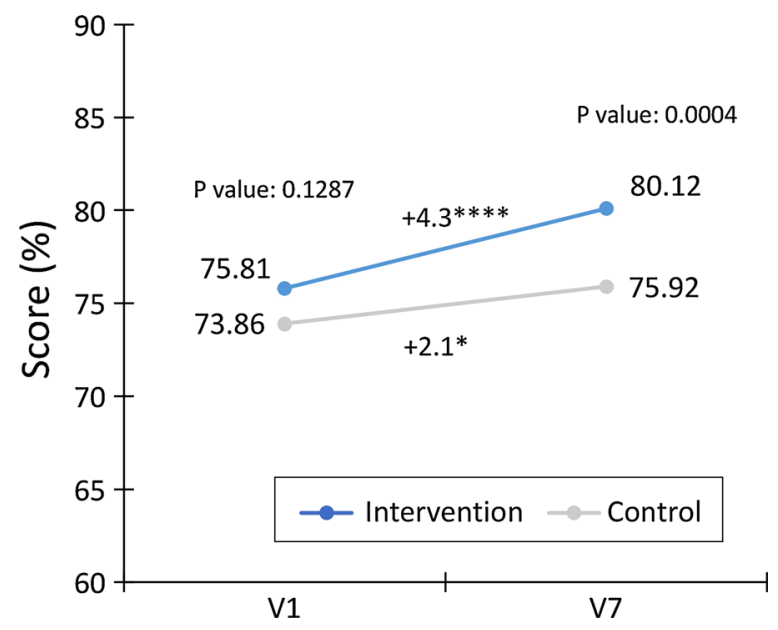

Fig. 2 Change in global TOP scores (\%) from baseline (V1) to 6 months (V7) in the intervention and control groups. Within-group comparisons using Student's paired $t$-test: ${ }^{*} p<0.05 ;{ }^{* * * *} p<0.0001$. Between-group comparisons using the ANOVA Fisher-Snedecor ( $p$ value)

assessed using quantitative methods (MPR and TOP score). The quantitative measurement of pills showed good levels of adherence to medication at baseline, with no difference between the intervention and control groups. This can be explained by the fact that a significant proportion-almost one-third of patients at inclusion in our study-had a personal pilldispensing device [25]. Such devices facilitate medication adherence and may explain the high scores observed at both the beginning and end of the first study period (6 months) $[25,26]$. TOP scores were also high at baseline in both groups, indicating a "good ability to self-manage treatment" based on TOP criteria results. However, although medication adherence was already good, HbA1c levels at baseline were $>$ $7 \%$ for the vast majority of patients (>98\% in both groups). Therefore, other factors, such as inadequate combination therapies, comorbidities and inappropriate lifestyles (low levels of physical activity and inadequate dietary practices), may explain why treatment targets were not being achieved [18, 27-29]. Our intervention consisted of delivering structured information on three topics (diabetes diet, medication management and diabetes complications) followed by an open and tailored dialogue between the pharmacist and the patient. In the intervention group, TOP scores were higher at 6 months than at baseline, which likely reflects an improved quality of interaction between the patient and the pharmacist gained through the interviews and an increase in the level of disease knowledge among patients together with better daily management of their treatment. Any of the intervention-driven improvements in patient-pharmacist communication, understanding of medication and treatment as well as good lifestyle habits may be responsible for the improvement of diabetes control in the population studied [30, 31]. Indeed, the reductions in HbA1c levels among the patients from the intervention group of $0.5 \%$ in the first 6 months and $0.6 \%$ after 1 year are an encouraging achievement with meaningful clinical consequences. This HbA1c improvement was not a consequence of changes in treatment between the first visit and the last visit after 1 year as no statistically significant differences in treatment changes were observed between the intervention group and the control group.

Table 3 Disease knowledge acquisition results

\begin{tabular}{llll}
\hline Number of correct answers $($ mean \pm SD) & Intervention group & Control group & $\boldsymbol{p}$ value $^{\mathbf{a}}$ \\
\hline Baseline & $8.3 \pm 1.3$ & $7.9 \pm 1.3$ & 0.0770 \\
6 months $(n=139)$ & $8.9 \pm 1.0$ & $8.2 \pm 1.2$ & 0.0002 \\
Difference from baseline, \% (95\% CI) & $0.6 \pm 1.4(0.3-1.0)$ & $0.3 \pm 1.5(0.07-0.7)$ & 0.2074 \\
12 months $(n=132)$ & $8.8 \pm 1.2$ & $8.0 \pm 1.3$ & 0.0003 \\
Difference from baseline, \% (95\% CI) & $0.7 \pm 1.5(0.3-1.0)$ & $0.2 \pm 1.5(-0.20$ to 0.6$)$ & 0.0976 \\
\hline
\end{tabular}

${ }^{a}$ Between-group comparisons of means: analysis of variance (ANOVA Fisher-Snedecor) 
A recent literature review [24] found that interventions performed by pharmacists had a positive impact on T2D management, including HbA1c level. Indeed, among 26 RCTs assessing HbA1c levels, 24 showed a significant reduction of $0.18-2.1 \%$ in HbA1c levels, after an average interval of 3-12 months, between the control and the intervention groups [24]. Recently, in Cyprus, Korcegez et al. observed an HbA1c reduction of $0.74 \%$ at 12 months with a similar approach and method to those performed in our study [23]. As expected, the largest decreases were found in groups with high initial HbA1c levels $(>8.5 \%)$. This was also the case in other studies reviewed by Pousinho et al.-i.e., the largest differences in the change in HbA1c levels (HbA1c level differences $>1 \%$ ) between groups were reported for patients with HbA1c levels $>$ 9\% at baseline. Despite T2D being relatively well controlled in our study population (mean baseline HbA1c 7.8\%), our results are in agreement with those of these previous studies using an IMB Fischer approach in terms of the education/information delivered to patients by the pharmacist [22, 24]. In contrast, some pharmacist intervention studies have not demonstrated any improvement in HbA1c $[29,32]$. We believe that a major factor explaining the improvement in glycemic control in the intervention group in our study was a better basic understanding of the disease and its treatment by patients, together with a better "acceptance" of the need to ensure reasonable day-to-day management of the disease. For some patients, there may be a virtuous cycle of improvement once they are involved in such a program, inducing active engagement in other healthy lifestyle behaviors as suggested by Bruckert et al. [33]. The positive outcomes reported in our study may also be directly related to the observed improvements in diabetes knowledge demonstrated by the improvement in the number of correct answers to the knowledge acquisition questionnaire, thus allowing patients to develop their practical knowledge of diabetes and to put it into practice in their daily life [34-36]. It is noteworthy that the second period of the IPHODIA study was characterized by small, but further improvement of patient knowledge at 12 months. LDL-c levels did not change during the two study phases; however, basal values were already close to international recommended values, leaving little or no room for further improvement at 6 or 12 months [37]. There is no consistent evidence in the literature indicating that patient LDL-c levels benefit from educational programs delivered by pharmacists [38-40].

Our data thus support the hypothesis that, even in patients "adherent to treatment," glycemic control can be improved by a structured and tailored information program delivered by community pharmacists.

Our study had some limitations. First, there was no centralized measurement of $\mathrm{HbA1c}$ in this study, a situation inherent to such a reallife study strategy. There was also potential for participation bias at the level of the pharmacist, although this was limited by randomizing groups of pharmacists between the intervention and control groups. To reduce patient participation bias, randomization was performed at the level of the pharmacies, and all patients in the intervention pharmacies were proposed to benefit from the information program, whereas they were not in the control pharmacies.

Furthermore, although the final sample of pharmacies was representative of French pharmacies nationwide in terms of geographic distribution and size (annual turnover) according to national available figures from the French pharmacist authority, a selection bias at the patient level could have occurred and the study population could be not truly representative of the general T2D population. Indeed, agreement to participate in the study for the patients in both groups suggests that they could be particularly motivated and favorable to taking care of their health and hence could be more compliant with their treatment. This bias, however, is present in any patient education program. Advice tends naturally to be more conscientiously followed by those who are already pre-disposed to make an effort and prioritize attention to take care of their own health. The high medication adherence level at baseline may reflect this potential selection bias. However, our data do indicate that this intervention is valuable, even in T2D patients who already show good medication adherence. 
Our newly developed questionnaires have been tailored for a study involving community pharmacists, and even if some improvements could be made to this program, we have been able to measure meaningful positive changes in both disease literacy and dietary behavior.

\section{CONCLUSION}

In conclusion, pharmacists can make a positive contribution to management of T2D patients with a direct impact on glycemic control, patient knowledge about diabetes and the quality of the patient-pharmacist relationship. Our study demonstrates, in agreement with other studies, that a simple intervention with a series of three 30-min interviews after drug dispensation may significantly decrease HbA1c levels within a 1-year period. This is a clinically important given that $>40 \%$ of diabetic patients in France, and elsewhere [6], are not meeting their treatment targets and have HbA1c levels > $7 \%[3,4]$.

\section{ACKNOWLEDGEMENTS}

We gratefully acknowledge the patients and pharmacists for their enthusiastic participation in this study.

Funding. Sponsorship for this study, article processing charges and Open Access were funded by MSD France. All authors had full access to all of the data in this study and take complete responsibility for the integrity of the data and accuracy of the data analysis.

Medical Writing Assistance. We gratefully acknowledge Nessryne Sater, Emma Pilling and Marielle Romet (Santé Active Edition) for providing assistance in medical writing and language editing. This was funded by MSD France.

Authorship. All named authors meet the International Committee of Medical Journal Editors (ICMJE) criteria for authorship for this article, take responsibility for the integrity of the work as a whole and have given their approval for this version to be published.

Disclosures. Bruno Vergès received a grant from MSD France, as the main investigator of this study. Yves Michiels received support from MSD, Biogen and Observia. Sylvie Dejager is an employee of MSD France who funded this study. Catherine Hunault is an employee of MSD France who funded this study. Chrsitine Moisan was an MSD France employee at the time of the study. Laura Romengas is an Observia employee. Observia is the service Provider tasked with monitoring the study. Hubert Méchin is an Observia employee. FrançoisAndré Allaert received a grant from Observia, and is employed by Cenbiotech, who did the statistical part of the study. Annie Chicoye and Olivier Bugnon have nothing to disclose.

Compliance with Ethics Guidelines. The study was conducted in accordance with the Declaration of Helsinki. The study protocol was submitted to the Committee for the Protection of Persons (CPP Centre Est 1-Dijon), which considered that no informed consent was required according to the French law. As per law, approval for processing of health personal data was obtained from the French Data Protection Agency following prior consultation of the Advisory Committee on Data Processing in Health Research, which raised a favorable opinion.

Data Availability. The datasets during and/ or analyzed during the current study are available from the corresponding author on reasonable request.

Open Access. This article is distributed under the terms of the Creative Commons Attribution-NonCommercial 4.0 International License (http://creativecommons.org/licenses/ by-nc/4.0/), which permits any noncommercial use, distribution, and reproduction in any medium, provided you give appropriate credit to the original author(s) and the source, provide a link to the Creative Commons license, and indicate if changes were made. 


\section{REFERENCES}

1. Riddle MC, Herman WH. The cost of diabetes care-an elephant in the room. Diabetes Care. 2018;41:929-32.

2. de Lagasnerie G, Aguade AS, Denis P, Fagot-Campagna A, Gastaldi-Menager C. The economic burden of diabetes to French national health insurance: a new cost-of-illness method based on a combined medicalized and incremental approach. Eur J Health Econ. 2018;19:189-201.

3. Fagot-Campagna A, Fosse S, Roudier S, et al. Caractéristiques, risque vasculaire et complications chez les personnes diabétiques en France métropolitaine: d'importantes évolutions entre Entred 2001 et Entred 2007. Bull Epidemiol Hebd. 2009;2009:2009.

4. de Pablos-Velasco P, Parhofer KG, Bradley C, et al. Current level of glycaemic control and its associated factors in patients with type 2 diabetes across Europe: data from the PANORAMA study. Clin Endocrinol (Oxf). 2014;80:47-56.

5. Ali MK, Bullard KM, Gregg EW. Achievement of goals in U.S. Diabetes Care, 1999-2010. N Engl J Med. 2013;369:287-8.

6. Edelman SV, Polonsky WH. Type 2 diabetes in the real world: the elusive nature of glycemic control. Diabetes Care. 2017;40:1425-32.

7. Krapek K, King K, Warren SS, et al. Medication adherence and associated hemoglobin A1c in type 2 diabetes. Ann Pharmacother. 2004;38:1357-62.

8. Wild $\mathrm{H}$. The economic rationale for adherence in the treatment of type 2 diabetes mellitus. Am J Manag Care. 2012;18:S43-8.

9. Rosen MI, Rigsby MO, Salahi JT, Ryan CE, Cramer JA. Electronic monitoring and counseling to improve medication adherence. Behav Res Ther. 2004;42:409-22.

10. Guillausseau PJ. Influence of oral antidiabetic drugs compliance on metabolic control in type 2 diabetes. A survey in general. Diabetes Metab. 2003;29:79-81 (/data/revues/12623636/00290001/79/.2008).

11. Kogut SJ, Andrade SE, Willey C, Larrat EP. Nonadherence as a predictor of antidiabetic drug therapy intensification (augmentation). Pharmacoepidemiol Drug Saf. 2004;13:591-8.

12. Boye KS, Curtis SE, Lage MJ, Garcia-Perez L-E. Associations between adherence and outcomes among older, type 2 diabetes patients: evidence from a Medicare Supplemental database. Patient Prefer Adherence. 2016;10:1573-81.

13. Winkler A, Teuscher AU, Mueller B, Diem P. Monotoring adherence to prescribed medication in type 2 diabetic patients treated with sulfonylureas. Swiss Med Wkly. 2002;132:379-85.

14. Alinia H, Feldman SR. Assessing medication adherence using indirect self-report. JAMA Dermatol. 2014;150:813-4.

15. Carls GS, Tuttle E, Tan R-D, et al. Understanding the gap between efficacy in randomized controlled trials and effectiveness in real-world use of GLP-1RA and DPP4 therapies in patients with type 2 diabetes. Diabetes Care. 2017;40:1469-78.

16. Aronson R, Orzech N, Ye C, Goldenberg R, Brown $\mathrm{V}$. Specialist-led diabetes registries and predictors of poor glycemic control in type 2 diabetes: Insights into the functionally refractory patient from the LMC Diabetes Registry database. J Diabetes. 2016;8:76-85.

17. Hsu C, Lemon JM, Wong ES, et al. Factors affecting medication adherence: patient perspectives from five veterans affairs facilities. BMC Health Serv Res. 2014;14:533.

18. Guénette L, Moisan J, Breton M-C, Sirois C, Grégoire J-P. Difficulty adhering to antidiabetic treatment: factors associated with persistence and compliance. Diabetes Metab. 2013;39:250-7.

19. Chang SJ, Choi S, Kim S-A, Song M. Intervention strategies based on information-motivation-behavioral skills model for health behavior change: a systematic review. Asian Nurs Res. 2014;8:172-81.

20. Osborn CY, Amico KR, Cruz N, et al. A brief culturally tailored intervention for Puerto Ricans with type 2 diabetes. Health Educ Behav. 2010;37:849-62.

21. Butt M, Mhd Ali A, Bakry MM, Mustafa N. Impact of a pharmacist led diabetes mellitus intervention on HbA1c, medication adherence and quality of life: A randomised controlled study. Saudi Pharm J (SPJ). 2016;24:40-8.

22. Mehuys E, Van Bortel L, De Bolle L, et al. Effectiveness of a community pharmacist intervention in diabetes care: a randomized controlled trial. J Clin Pharm Ther. 2011;36:602-13.

23. Korcegez EI, Sancar M, Demirkan K. Effect of a pharmacist-led program on improving outcomes in patients with type 2 diabetes mellitus from northern Cyprus: a randomized controlled trial. J Manag Care Spec Pharm. 2017;23:573-82. 
24. Pousinho S, Morgado M, Falcão A, Alves G. Pharmacist interventions in the management of type 2 diabetes mellitus: a systematic review of randomized controlled trials. J Manag Care Spec Pharm. 2016;22:493-515.

25. Morello CM, Chynoweth M, Kim H, Singh RF, Hirsch JD. Strategies to improve medication adherence reported by diabetes patients and caregivers: results of a taking control of your diabetes survey. Ann Pharmacother. 2011;45:145-53.

26. Liu AY, Hessol NA, Vittinghoff E, et al. Medication adherence among men who have sex with men at risk for HIV infection in the United States: implications for pre-exposure prophylaxis implementation. AIDS Patient Care STDs. 2014;28:622-7.

27. Scheen AJ. Pharmacotherapy of 'treatment resistant' type 2 diabetes. Expert Opin Pharmacother. 2017;18:503-15.

28. Crowley MJ, Holleman R, Klamerus ML, Bosworth HB, Edelman D, Heisler M. Factors associated with persistent poorly-controlled diabetes mellitus (PPDM): clues to improving management in patients with resistant poor control. Chronic Illn. 2014;10:291-302.

29. Cohen LB, Taveira TH, Khatana SAM, Dooley AG, Pirraglia PA, Wu W-C. Pharmacist-led shared medical appointments for multiple cardiovascular risk reduction in patients with type 2 diabetes. Diabetes Educ. 2011;37:801-12.

30. Aikens JE, Piette JD. Diabetic patients' medication underuse, illness outcomes, and beliefs about antihyperglycemic and antihypertensive treatments. Diabetes Care. 2009;32:19-24.

31. Piette JD, Schillinger D, Potter MB, Heisler $M$. Dimensions of patient-provider communication and diabetes self-care in an ethnically diverse population. J Gen Intern Med. 2003;18:624-33.

32. Simpson SH, Majumdar SR, Tsuyuki RT, Lewanczuk RZ, Spooner R, Johnson JA. Effect of adding pharmacists to primary care teams on blood pressure control in patients with type 2 diabetes: a randomized controlled trial. Diabetes Care. 2011;34:20-6.

33. Bruckert E, Masana L, Chapman MJ, Descamps O, Bosi E, Allaert FA. Dietary supplementation contributes to lifestyle improvement in hypercholesterolemic patients in real-life contexts. Curr Med Res Opin. 2014;30:1309-16.

34. Chrvala CA, Sherr D, Lipman RD. Diabetes selfmanagement education for adults with type 2 diabetes mellitus: a systematic review of the effect on glycemic control. Patient Educ Couns. 2016;99:926-43.

35. Heald AH, Livingston $\mathrm{M}$, Malipatil $\mathrm{N}$, et al. Improving type 2 diabetes mellitus glycaemic outcomes is possible without spending more on medication: lessons from the UK national diabetes audit. Diabetes Obes Metab. 2017;20:185-94.

36. Kostoff MD, Boros ML, Moorman JM, Frazee LA. Evaluation of factors associated with achieving glycemic control in a pharmacist-managed diabetes clinic. Am J Ther. 2014;21:234-9.

37. Garber AJ, Abrahamson MJ, Barzilay JI, et al. Consensus statement by the American Association of Clinical Endocrinologists and American College of Endocrinology on the comprehensive type 2 diabetes management algorithm-2016 executive summary. Endocr Pract. 2016;22:84-113.

38. Chan C-W, Siu S-C, Wong CKW, Lee VWY. A pharmacist care program: positive impact on cardiac risk in patients with type 2 diabetes. J Cardiovasc Pharmacol Ther. 2012;17:57-64.

39. Lee JK, Grace KA, Taylor AJ. Effect of a pharmacy care program on medication adherence and persistence, blood pressure, and low-density lipoprotein cholesterol: a randomized controlled trial. JAMA. 2006;296:2563-71.

40. Fornos JA, Andrés NF, Andrés JC, Guerra MM, Egea B. A pharmacotherapy follow-up program in patients with type-2 diabetes in community pharmacies in Spain. Pharm World Sci (PWS). 2006;28:65-72. 